\title{
Moda e vestuário nos periódicos femininos brasileiros do século XIX
}

\author{
[Fashion and garment in the Brazilian female periodicals from the I9th century
}

\author{
Beatriz Albarez de Assunção ${ }^{x}$ \\ Isabel Cristina Italiano ${ }^{2}$
}

RESUMO - Este artigo tem o objetivo de apresentar uma primeira relação entre moda e imprensa no Brasil oitocentista, além da importância dada ao vestuário feminino nos periódicos brasileiros do século XIX. No acervo da Biblioteca Nacional, escolheram-se os periódicos O Espelho Diamantino, O Jornal das Senhoras e A Estação, levando em consideração uma evolução cronológica e de conteúdo. A partir disso foram selecionadas as edições mais relevantes para discutir os temas recorrentes. Como resultado, foi possível depreender que: a diferença climática entre Brasil e Europa foi o principal empecilho na importação de moda; os periódicos oitocentistas, que são importante fonte de documentação da história da moda, porém não da moda brasileira, atuaram também como impulso para mudanças no vestuário, criando tanto um mercado de moda como de imprensa. PALAVRAS-CHAVE - Moda; periódicos; século XIX; Brasil. • ABSTRACT · This article aims to present a first approach between the fashion and the Brazilian press in the nineteenth-century, and also the importance given to the female garment in the Brazilian periodicals. From the National Library's collection the chosen periodicals are "O Espelho Diamantino", "O Jornal das Senhoras" and "A Estação", taking into account a chronological and content evolution. From these, the most relevant editions were selected to discuss the iterant subject. As a result, it was possible to understand that the climate difference between Brazil and Europe has been identified as the main obstacle for fashion; nineteenthcentury periodicals are an important source of documentation of the history of fashion, but not of a Brazilian fashion; they also acted as the impetus for changes in fashion and, thus, creating either a fashion as a press market. • KEYWORDS · Fashion; periodicals; nineteenth century; Brazil.

Recebido em 22 de março de 2018

Aprovado em 8 de outubro de 2018

ASSUNÇÃO, Beatriz Albarez de; ITALIANO, Isabel Cristina. Moda e vestuário nos periódicos femininos brasileiros do século XIX. Revista do Instituto de Estudos Brasileiros, Brasil, n. 7I, p. 232-25I, dez. 2018.

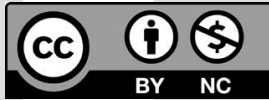

DOI: http://dx.doi.org/Io.II606/issn.23I6-9oIX.voi7Ip232-25I

I Universidade de São Paulo (USP, São Paulo, SP, Brasil).

2 Universidade de São Paulo (USP, São Paulo, SP, Brasil). 


\section{O SÉCULO XIX, A MODA E A IMPRENSA FEMININA}

No início do século XIX a vinda da Corte portuguesa para o Brasil, fugindo das invasões francesas, intensificou a importação de artigos europeus tanto pela própria Corte quanto pela elite que então se alocava na colônia. Esse cenário de importação foi também impulsionado pela proibição de manufaturas têxteis por D. Maria I, a Louca, a fim de proteger a economia do ouro brasileiro. Desde esse momento a moda estrangeira ganharia um espaço de destaque que se estenderia até a década de I950, quando começaram a surgir os primeiros estilistas e costureiros nacionais e, com eles, um início de um estilo brasileiro, ainda que a vinda da Corte para o país tivesse desencadeado o início das cópias de modelos (BRAGA; PRADO, 20II).

Assim sendo, pode-se dizer que o vestuário no Brasil do século XIX seguiu o vestuário europeu, em especial o francês, sendo possível identificar novas modas em um intervalo de dez anos. No início do século, os vestidos brancos, decotados, com a cintura bem alta e soltos no corpo seguiam o sentimento de libertação pós-Revolução Francesa, mas já a partir de 1820 aparecem novos elementos no vestuário: as saias se abrem; as mangas se tornam mais bufantes; a cintura abaixa e afina-se (volta do espartilho); só não se abandonou o uso do xale, que foi e voltou à moda várias vezes durante o século (BOUCHER, 20Io; LAVER, I989). Por volta de I830, as mangas foram ficando cada vez maiores e não se limitavam ao ombro, muitas vezes desciam até os punhos; as saias ficaram ligeiramente mais curtas e o uso de grandes chapéus e sombrinhas era muito comum. Já em I840 as saias rodadas cobrem novamente os tornozelos, e os chapéus passam a ser do tipo boneca. A partir dessa década usaram-se várias anáguas para dar volume às saias, dificultando o movimento da mulher (LAVER, I989).

Na metade do século surgiu a "crinolina de armação" (LAVER, I989), formada de arcos de aço flexível, para substituir as anáguas e diminuir o peso carregado pelas mulheres. Ao mesmo tempo os vestidos se tornavam mais extravagantes, com laços, flores, rendas e babados nas saias e mangas. Em I860 a crinolina se deslocou para trás, deixando a frente do vestido mais reta e, aos poucos, foi se transformando em uma anquinha ao final dessa década. As anquinhas marcam a década seguinte, formando uma cauda na parte de trás dos vestidos, com a saia unida - ou não - 
ao corpete e com a opção de usar uma sobressaia. Em I880 essa peça tornou-se horizontalmente maior, enquanto a cintura estava cada vez mais fina com a ajuda de um corpete-espartilho; mais uma vez os chapéus voltaram a chamar a atenção, com plumas, flores e outros adornos. Por fim, em I890, as anquinhas desapareceram, as saias continuaram compridas, porém em forma de sino, e as golas altas, com babados de renda; as mangas eram grandes, precisando até de enchimentos; usavam-se luvas compridas, botas, sapatilhas e muitas joias (LAVER, I989).

A descrição de Braga e Prado (20II) sobre o vestuário no período da República Velha ${ }^{3}$ e belle époque mostra a mulher brasileira com uma aparência bem francesa: silhueta ampulheta, saias longas, laços e bordados, a obrigatoriedade da sombrinha para manter a aparência pálida, sapatos fechados, chapéus extravagantes e, ainda, com uma linha de etiqueta do vestir.

Em $O$ espírito das roupas: a moda no século dezenove (SOUZA, I987), há algumas imagens que mostram o típico vestuário do final do século XIX no Brasil, as quais estão em conformidade com a descrição de Braga e Prado (2OII) de que os vestidos usados pelas mulheres brasileiras seguiam a moda oitocentista europeia: as mangas bufantes e lisas, que chegavam aos punhos ou até a metade dos braços; as saias com crinolina, com anquinhas e caudas; os babados e camadas; as golas que lembram rufos e também as mais achatadas.

Toda essa cultura de moda e vestir conquistou espaço nos periódicos da época, que se tornavam fonte principal de informação para a sociedade. Na Europa, moldes de peças de vestuário já eram impressos e vendidos e, por mais que a moda pareça ser mais intensa para as mulheres, os primeiros periódicos de moda eram voltados para o público masculino. Já no século XIX, a França e a Inglaterra possuíam inúmeras publicações, algumas delas alcançando grande número de vendas, como o francês Petit Echo de La Mode (I878), que vendeu cerca de 2Io mil exemplares em I893 (BRAGA; PRADO, 2OII).

A circulação de periódicos de moda em território brasileiro teve início com os periódicos franceses e portugueses, trazidos para o país após a chegada da Corte em I808. Na época, a baixa alfabetização feminina contribuía para a pouca circulação de periódicos para esse público, mas, com a pequena mudança desse cenário após a independência, surgiam periódicos nas principais cidades brasileiras, dentre eles: O Espelho Diamantino (I827), Espelho das Brasileiras (I83I), O Correio das Modas (I839), O Jornal das Senhoras (I852), Jornal das Famílias (I863). É bom lembrar que esses periódicos não se restringiam apenas ao vestuário, mas também continham as informações necessárias para que uma mulher da época tivesse um comportamento de acordo com as regras sociais; havia informações de teatro, música, arte, etiqueta e também pequenos contos e romances folhetins (BRAGA; PRADO, 20II).

Os periódicos de moda do século XIX são o objeto de pesquisa por surgirem no país pela primeira vez no início desse século, sendo, portanto, um novo meio de comunicação e, consequentemente, registro histórico da moda do período oitocentista. Eles ainda representam um avanço na imprensa brasileira e também mundial. A disseminação de informações foi facilitada em um nível jamais

3 Período da história brasileira que vai da Proclamação da República, em I5 de novembro de I889, até a Revolução de I930. 
alcançado no país: a intensa comunicação entre países permitiu que as culturas se interligassem formando redes, que possibilitariam o fenômeno da globalização. Que foi exatamente o que aconteceu com a moda. Uma peça típica de um país se espalhou juntamente com uma bagagem cultural, resumida em periódicos e tornando possível o acesso de grande parte da população brasileira a informações das potências da época: a França e a Inglaterra.

Este artigo tem o propósito de apresentar essa primeira relação entre moda e imprensa no Brasil oitocentista, com especial atenção para as diferentes abordagens dadas ao vestuário ao longo desse século em três periódicos que representam a evolução cronológica da imprensa voltada ao público feminino: O Espelho Diamantino, O Jornal das Senhoras e A Estação. Tais publicações foram levantadas a partir da plataforma on-line da Biblioteca Nacional, a Hemeroteca Digital; a partir de uma seleção de conteúdos, estes foram analisados e discutidos com base nas obras de François Boucher, James Laver, Carlos Costa e Dulcília Buitoni, de acordo com os pontos que mais se destacavam nos periódicos.

\section{O Espelho Diamantino (1827)}

De acordo com Costa (2012), O Espelho Diamantino foi publicado por apenas um ano e contou com I3 edições. Em sua primeira edição (Figura I), o periódico "de política, litteratura, bellas artes, theatro e modas”, editado pelo francês Pierre Plancher, apresenta sua proposta em apenas quatro páginas. 


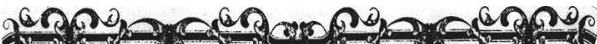

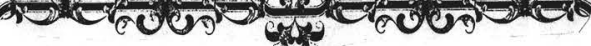
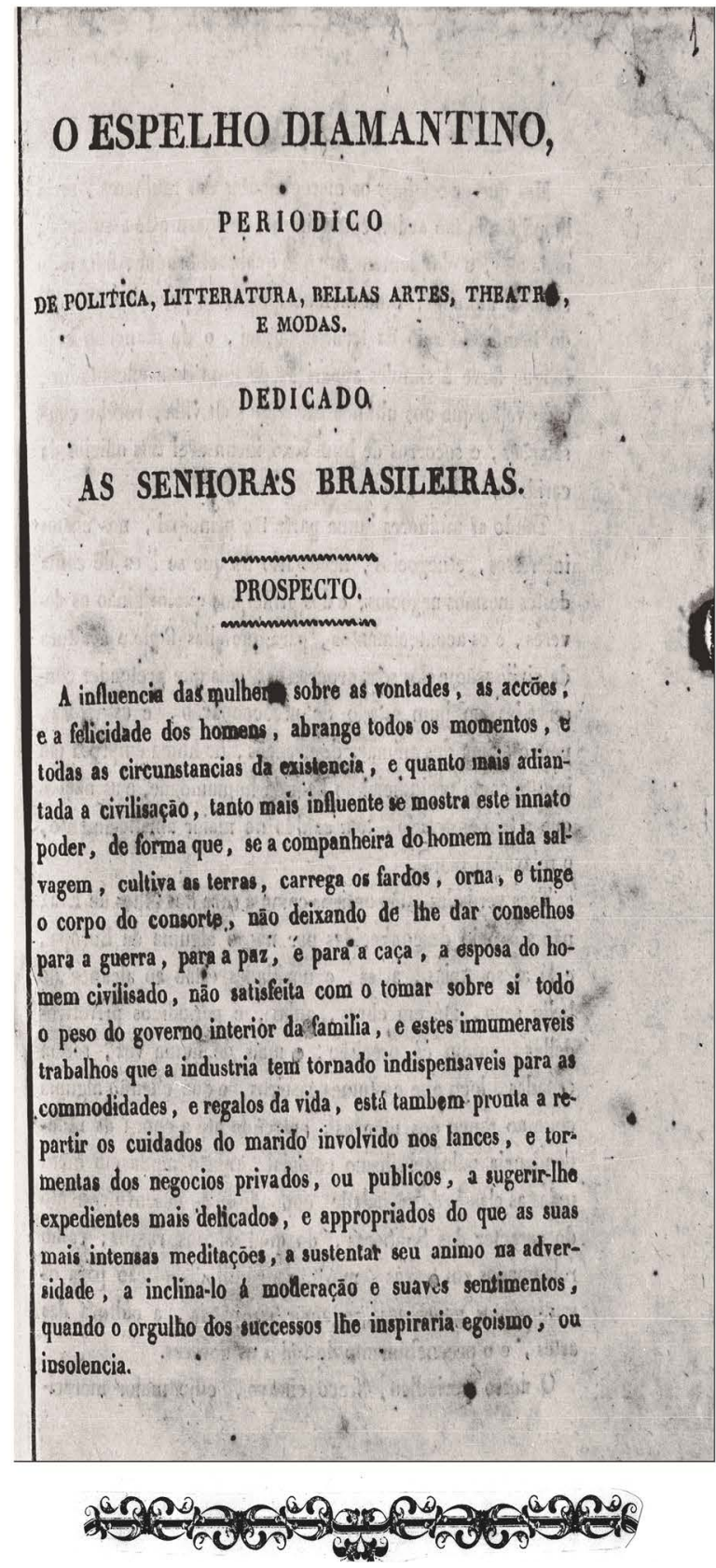

Figura I - O Espelho Diamantino, n. I, I827, p. I. Fonte: Hemeroteca Digital 
A apresentação do periódico anuncia que será publicado duas vezes ao mês e define os assuntos a serem tratados nas edições futuras. Quanto à moda, não há no momento a publicação de ilustrações no Brasil, portanto o periódico contém apenas descrições de modelos. Ele explica: "A respeito das modas, artigo privativo das Senhoras, seria hum crime em nós, e quasi um sacrilégio, se as omittindo, deixassemos de render hum culto á Caprichosa Deos, cujos decretos, por mais variaveis e impertinentes que sejão, veem-se cegamente obedecidos” (O ESPELHO Diamantino, n. I, I827, p. 3-4) 4 .

Na segunda edição, a coluna Modas dedica um simples parágrafo para atualizar as senhoras quanto ao que vestir: "As Modas, nestes ultimos dez dias não offerecem variação notavel. As cinturas cumpridas, e mangas de gigot estão na mesma aceitação [...]. Os vestidos de négligé de chita franceza e riscados tranparentes, com frangidos, e fofos da mesma peça, ornão quasi todas as lojas" (O ESPELHO Diamantino, n. 2, I827, p. 3I).

Nesse trecho destacado, pode-se perceber como os elementos do vestuário permaneciam na moda por longo tempo: as mangas de gigot (amplas acima do cotovelo e justas nos braços), que apareceram no início da década de I820 - como colocada por Boucher (20I0) - continuam em vigor em I827.

Duas edições depois, o editor faz uma crítica à importação de modelos vindos do estrangeiro. Os artigos de vestuário que chegavam ao Brasil eram considerados velhos, uma moda já deixada de lado na França - que é o país em questão tratado no periódico. Na coluna de moda da $5^{a}$ edição de I827- que será a última coluna dedicada ao assunto nesse periódico - há um pequeno trecho que se refere à divergência de clima entre Europa e América do Sul: "Eis o tempo quente. A moda das calças de pano e dois coletes continua com todo furor! Quanto mais longe do commodo e razoavel, melhor!” (O ESPELHO Diamantino, n. 5, I827, p. 83). Tal diferença climática tinha impacto negativo em relação ao conforto proporcionado pelas vestimentas importadas.

\section{O JORNAL DAS SENHORAS (1852)}

O Jornal das Senhoras é considerado o primeiro periódico voltado ao público feminino editado e redigido apenas por mulheres. Inicialmente estava nas mãos da professora argentina Joana de Noronha, era publicado semanalmente aos domingos e teve curta vida de publicação de apenas quatro anos.

4 Na transcrição dos textos dos periódicos, foram mantidas a grafia e a pontuação originais. 


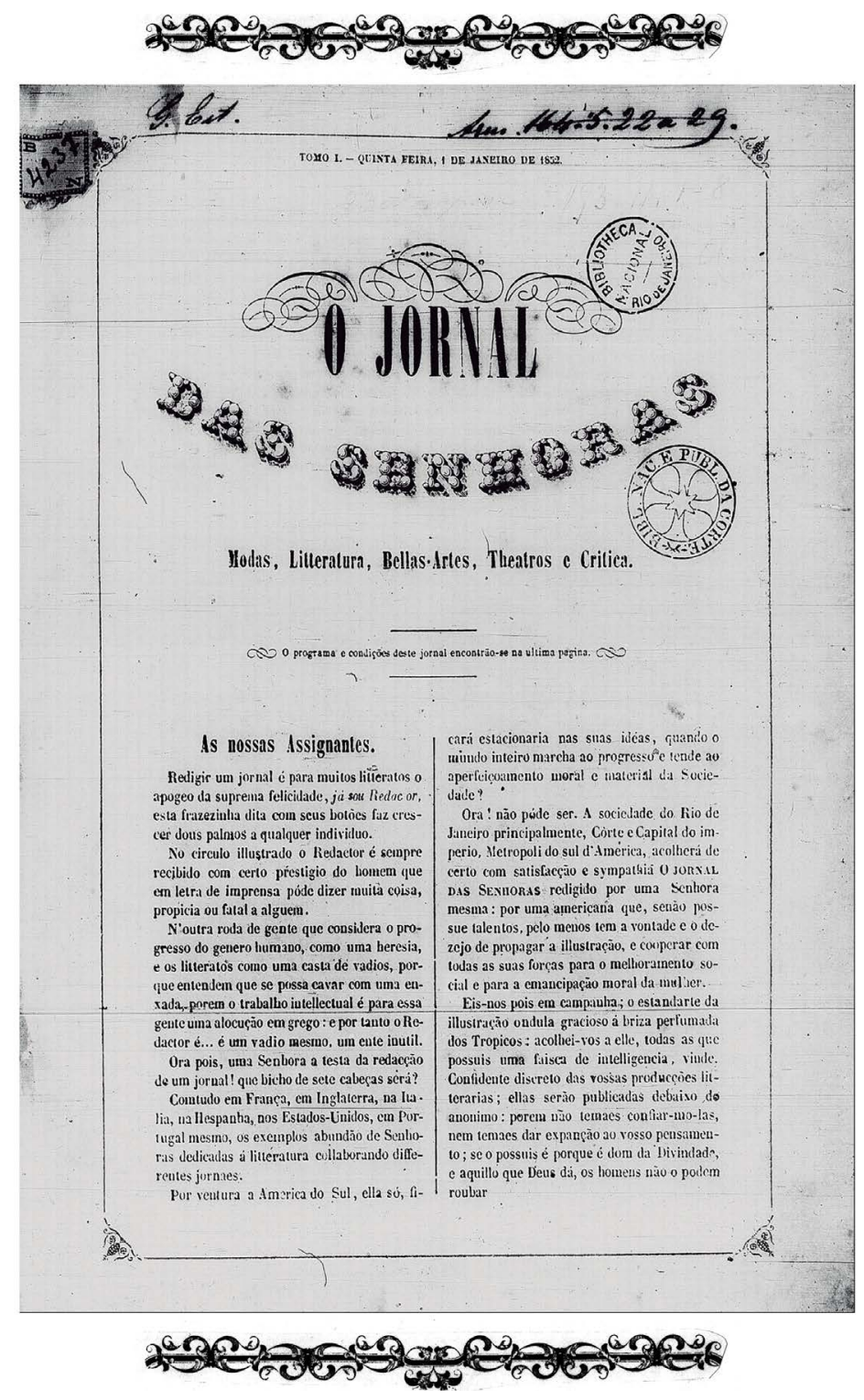

Figura 2 - Primeira página com cabeçalho de $O$ Jornal das

Senhoras, n. I, I852, p. I. Fonte: Hemeroteca Digital

Em sua primeira edição do ano de I852 (Figura 2), a coluna de moda - escrita em formato de carta e assinada por Christina - contém uma descrição detalhada de um figurino de baile anexado ao periódico o qual, infelizmente, não está disponível para consulta on-line. Sabe-se que uma ilustração de moda - ou estampa, como era 
chamada pela redatora - era anexada todo primeiro domingo do mês, segundo informa a mesma edição do periódico

Publica-se todos os DOMINGOS; o primeiro numero de cada mez vae acompanhado de um lindo figurino de mais bom tom em Paris, e os outros seguintes de um engraçado lundú ou terna modinha brasileira, romances francezes em musica, moldes e riscos de bordados. (O JORNAL das Senhoras, n. I, I852, p. 8).

Na quinta edição, Christina, questionada quanto à inversão das estações da França em relação ao Brasil e também quanto aos tecidos empregados na confecção dos modelos apresentados no periódico, faz uma crítica à tentativa de brasileiras criarem modelos, afirmando que apenas os franceses são capazes de criar moda. Ela, portanto, diz que:

Não é feito aqui no Rio de Janeiro, porque Deus não nos deu o dom especial de idear, combinar, e executar modas com essa graça, originalidade e gosto delicado, que para ellas tem os Parisienses, e ninguem mais. Temos sim actualmente quem os possa copiar com perfeição (ja não é tão pouco) mas a invenção é, e será sempre dos Francezes. (O JORNAL das Senhoras, n. 5, I852, p. 34).

Ao descrever as partes do figurino apresentado nessa mesma edição, também promete às leitoras que irá disponibilizar os moldes das partes da saia para que possam confeccioná-la em casa. Mesmo sendo um modelo volumoso, Christina o descreve como

[...] acommodado á nossa estação, gracioso e leve e de pequena despeza [...] mui notavel pela sua naturalidade e o nenhum espalhafato dos caprichos fantasticos [...]. O vestido é de cambrainha, chamada - Rosa d'a China. - Esta fasenda pela novidade da sua côr viva e brilhante, e ao mesmo tempo grave e de bom gosto, deve fazer effeito entre as elegantes de Paris na sua proxima primavera [...]. (O JORNAL das Senhoras, n. 5, I852, p. 34).

No segundo ano de publicação, em I853, a primeira edição conta com um modelo de vestido de noiva e de visita, com descrição muito bem detalhada de cada elemento de ambos os modelos. Percebe-se a grande quantidade de pequenos adornos que compõem o modelo como um todo: bordados, botões, fitas, flores, luvas, mangas, rendas... Todos esses elementos confirmam a moda da época de exageros de adereços no visual feminino.

[...] Corpo afogado, um pouco aberto adiante, e com abertura guarnecida em volta de renda de blond estreita deixando entrever uma camisinha, também afogada, de ponto de Inglaterra -Cintura redonda - Mangas compridas e meias largas, divididas em seis fôfos progressivos, com punhos lisos afunilados e presos com dois botões de perolas cada um - Uma larga fita branca chamalotada fingindo cabeção e ao mesmo tempo cinto de grandes pontas volantes, fórma o nobre e elegante ornamento deste vestido. Esta fita é toda guarnecida de uma rendinha de blond da largura de dois dedos [...]. (O JORNAL das Senhoras, n. I, I853, p. 2-3). 
Já em seu último ano de circulação, I855, a primeira edição não possui uma coluna para discutir a moda do momento, no entanto, tem uma descrição bastante objetiva dos modelos da ilustração. Ela contém um modelo de vestuário de estar em casa, um de passeio e um para crianças:

Vestuário de estar em casa. - Saia de nobreza ${ }^{5}$ verde.

Cazawech de veludo preto, enfeitado de galão, renda e botões.

Sub-mangas, camisinha e modestia de cambraia de linho, guarnecidas de valencianas. Vestuário de passeio. - Vestido de nobreza lisa: saia enfeitada com dous folhos guarnecidos de fita de veludo da mesma côr.

Mantelete ${ }^{6}$ da mesma fazenda, enfeitado tambem de igual veludo.

Chapéo de seda com blonde e flores. (O JORNAL das Senhoras, n. I, I855, p. 3).

A partir dessa descrição de vestuário de casa e de passeio (Figura 3), é possível notar maior quantidade de adornos e elementos que compõem o visual feminino de passeio. O volume da saia de passeio é acentuado com os dois folhos que a acompanham e recebe ainda mais atenção com adornos, como fitas. É interessante destacar a preocupação com a combinação de materiais e cores propostas ("veludo da mesma cor", "mantelete da mesma fazenda").

5 Tecido de seda (PUELLES, 20I4).

6 Tipo de lenço grande, servindo de pequena capa ou para cobrir a cabeça (PUELLES, 20I4). 


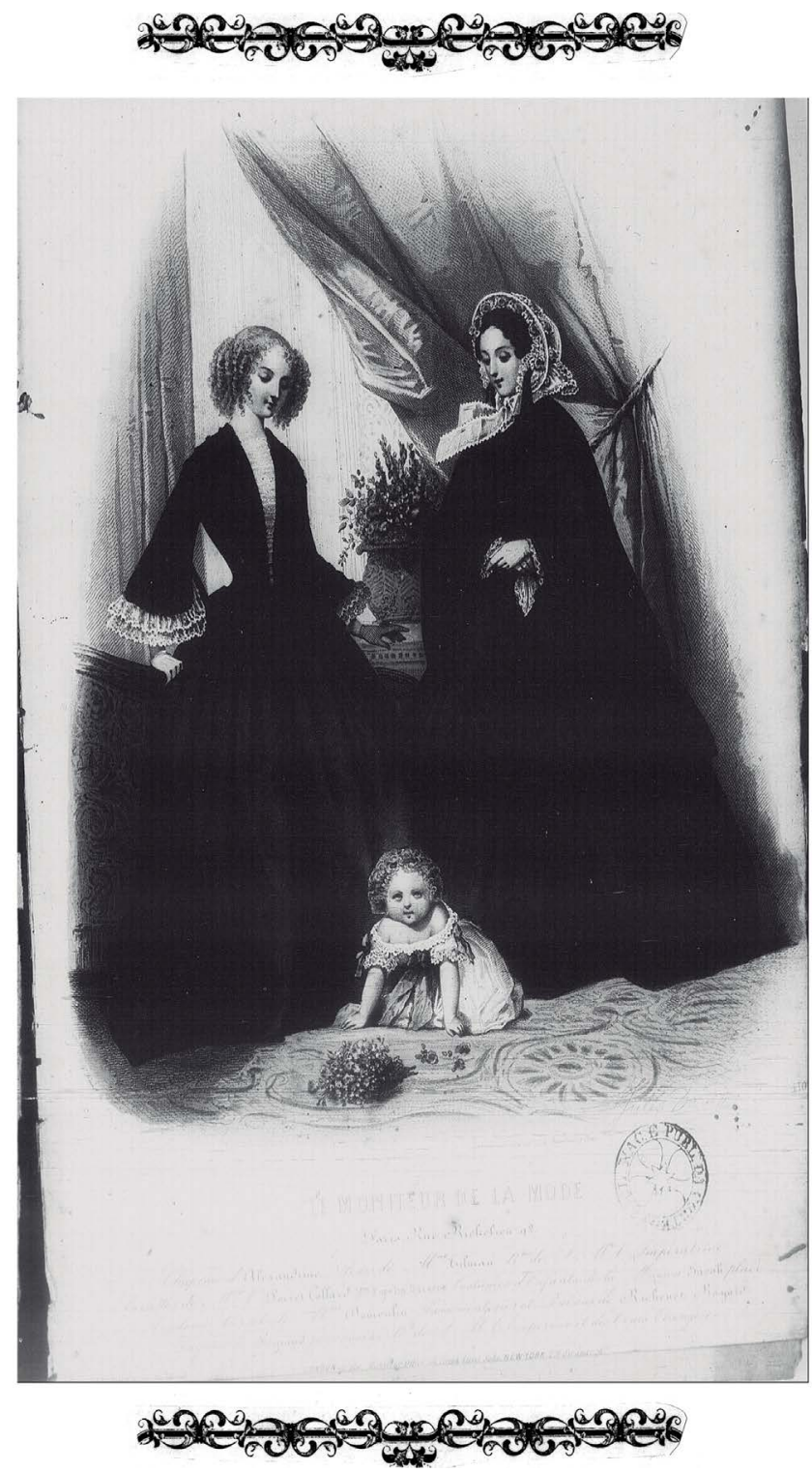

Figura 3-Vestuário de casa e de passeio. O Jornal das

Senhoras, n. I, I855, p. 7. Fonte: Hemeroteca Digital

Por fim, em seu último número a coluna Modas traz as tendências do inverno parisiense. Os chapéus continuam em uso, mas com copas pequenas, arredondadas e chatas, já que terão alguns adornos sobre a aba - como plumas, laços, rendas e veludos pretos. Também é discutido o uso das vasquinhas (saias que eram usadas sobre a roupa, pregueadas na cintura), algumas mulheres já não querem usá-las, mas outras - inclusive as modistas - defendem seu uso, uma vez que ajudam a alongar 
a silhueta; as saias continuam amplas e com caudas; os folhos duplos - babados - estão em moda nas mangas justas; por fim, as rendas pretas são o que dão elegância aos vestidos de soirée. A ilustração contém dois visuais - de casa e de passeio. Na descrição do de casa, pode-se perceber o papel da vasquinha, além de entender melhor a formação do folho:

\begin{abstract}
Vestuario de casa. - Penteado em cabellos; vestido em nobreza, corpinho com vasquinha muito justo decotado quadrado á Luiz XV com jockeys cruzados e mangas em filó de seda, as mangas compõem-se de dous entufados de filó retidos por dous crespos de fita e terminando com um duplo filó formando como um folho; o corpinho é cortado de maneira a bem fazer valer o talhe, e a vasquinha emboceta perfeitamente os quadris sem os achatar.

Vestuario de passeio. - Chapéo Rachel em tafetá recoberto de mousselina bordada guarnecido de valenciannas e ornado de botões de rosas. Vestido de nobreza ornado de veludos e de rendas; corpinho afogado mui justo, fechado adiante por botões de seda; suspensorios em veludo; a manga larga em baixo é quasi justa no hombro por baixo da renda e no meio é entufada e cortada ao longo por tres veludos; a saia é ornada de dous veludos retendo cada um uma alta renda ligeiramente pregada e por conseguinte tomando bem as pregas da saia que é mui ampla. (O JORNAL das Senhoras, n. 52, I855, p. 4IO).
\end{abstract}

\title{
A ESTAÇÃo (1879)
}

A Estação foi publicada no Brasil, pela Livraria e Tipografia Lombaerts e Comp., de I872 a I878, como uma tradução do periódico francês La Saison. Em I879 a edição brasileira continua com informações de moda europeia, porém com conteúdos de cultura locais, contando, por exemplo, com a publicação de Quincas Borba, de Machado de Assis, na seção de literatura. Esse periódico foi um dos que tiveram maior longevidade na época, circulando até I904 (COSTA, 2012).

Logo na primeira edição de I879 (Figura 4), A Estação é definida como sendo uma publicação indispensável para as mães de família que desejavam vestir suas filhas de acordo com os preceitos da época, preocupando-se com o que as mulheres achavam de suas publicações, como, por exemplo, se conseguiram alcançar o objetivo de ajudá-las a se vestir melhor sem ter que gastar mais. Também é interessante notar que o próprio periódico cita uma aceleração do ritmo de mudança de modas: "Antigamente a moda apenas mudava duas vezes ao anno [...] Hoje felizmente a moda, mesmo em Pariz, altera-se de dia para dia” (A ESTAÇÃO, n. I, I879, p. I). 


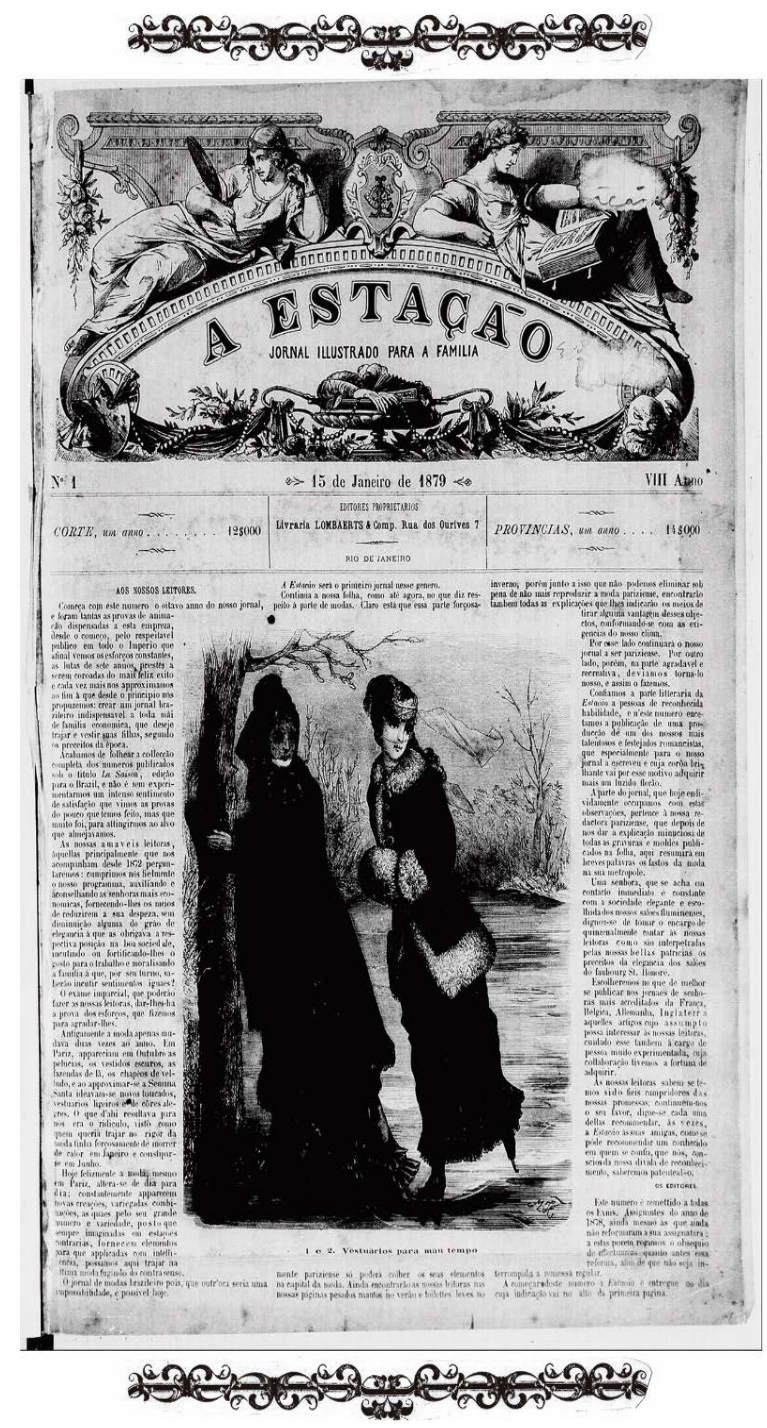

Figura 4-Capa de A Estação, n. I, I879, p. I. Fonte: Hemeroteca Digital

Na mesma edição, ainda confirmando a influência estrangeira na moda brasileira, os editores a mencionam direta e indiretamente, de modo negativo, ressaltando como as diferenças climáticas entre os países são um empecilho para seguir o estilo francês aqui no Brasil: "[em abril a moda francesa era para o verão, enquanto aqui se aproximava o inverno] [...] O que d'ahi resultava para nós era o ridiculo, visto como quem queria trajar no rigor da moda tinha que forçosamente tinha de morrer de calor em Janeiro e constipar-se em Junho" (A ESTAÇÃO, n. I, I879, p. I).

A Estação desejava não apenas informar as novidades internacionais em moda, mas também - principalmente, na verdade - ensiná-las como tirar proveito das peças de inverno que aqui chegavam no verão, e vice-versa, a fim de minimizar o 
sofrimento com as vestimentas vindas do estrangeiro. Pode-se colocá-lo como um dos primeiros periódicos a disponibilizar moldes para a confecção das peças.

Também foi um dos primeiros a propor uma identidade nacional à moda a partir de modificações de modelos de roupas francesas e inglesas: “[...] encontrarão tambem todas as explicações que indicarão os meios de tirar alguma vantagem desses objectos, conformando-se com as exigencias do nosso clima", concluindo que "A Estação será o primeiro jornal nesse genero" (A ESTAÇÃO, n. I, I879, p. I).

Seu conteúdo de moda apresentava roupas infantis, vestidos para o dia, vestidos para festa, toucas, luvas e acessórios em geral. As várias ilustrações do periódico mostravam detalhes da peça e continham informações sobre sua confecção junto com referências para os moldes. A segunda edição de I879 se inicia com uma ilustração e descrição de dois trajes de baile vistos em Paris. São vestidos de duas peças com caudas longas, citados por Boucher (20I0), muito comuns na década de I870, além da grande quantidade de babados, pregueados, fitas e flores que adornavam os modelos, também mencionados pelo autor.

Já em I889, a primeira edição descreve a moda do inverno francês, seguindo ainda a proposta inicial do periódico de adaptação de modelos para o estilo e clima brasileiro. Desse modo, no momento em que aqui é verão, também são indicados tecidos para confeccionar casacos de inverno - definidos como "capas para mau tempo" - de maneira que sejam impermeáveis e não tão quentes: "O traje que nos occupa é dos mais elegantes; de pequena seda riscada furta côres, e muito leve, usa-se tanto de verão como de inverno, não tem nada de quente e exige um outro traje por baixo [...]. Assim, escolhei um panno leve ou semi-espesso da côr que preferrides dae-o a impermeabilizar. D'este modo tereis uma capa ordinaria de forma ambulancia, sobre-casaca ${ }^{7}$, ou visita segundo o vosso gosto" (A ESTAÇÃO, n. I, I889, p. I). São três tipos descritos, mas todos os tecidos indicados para sua confecção têm a mesma característica: leveza. São, portanto, mais frescos que os tecidos utilizados na França na mesma época do ano.

Além de dar as diretrizes dos materiais, os redatores comentam os preços dos tecidos e concluem que os casacos são caros, especialmente o que se utiliza do tecido inglês impermeabilizado, o qual, porém, não deixa o ar circular e pode ser desconfortável às senhoras brasileiras. Assim, apresentam três dicas de qual usar dependendo de suas ocupações:

Ora se se tem que ficar todo um dia exposta a chuva é necessario tomar a capa ingleza. Se a volta do passeio, em carro ou depois do baile se receia a chuva, é mais commodo levar comsigo um caoutcouc leve.

Finalmente se as vossas occupações vos obrigam a sair todos os dias ou faça sol ou faça chuva o melhor é recorrer á capa impermeabilizada. (A ESTAÇÃO, n. I, I889, p. I).

Na segunda edição de I889, pode-se ler uma explicação em detalhes de como utilizar as folhas de moldes, praticamente como existem em algumas revistas atuais que também dispõem moldes aos leitores:

7 Casaco largo, comprido e abotoado até a cintura (PUELLES, 20I4). 
Lettras maiusculas e minusculas, algarismos e sinais *, :, +, , , marcam a juncção das differentes peças dos moldes: o asterisco *, marca a cava onde deve ser collocada a costura da manga, caso esta não tenha sido dada. Cruzes inclinadas X e pontos •, marcam as pregas, a primeira a dobra exterior que se volta sobre a segunda. Será indispensavel marcar todos os signaes d'um molde sobre a copia ou o decalque, assim como todas as indicações e as linhas dos revezes, da dobra da fazenda, do enfeite etc. As linhas parallelas marcam as fendas, os bolços, o traçado dos botões, das casas, enfim todos os detalhes necessarios á applicação do modelo. (A ESTAÇÃO, n. 2, I889, p. I6).

Nos gabaritos, partes pequenas da roupa eram dadas em molde inteiro (como mangas, por exemplo); partes maiores continham uma linha reta indicando dobra, e o restante da linha que indicava a peça continuava por cima de outra parte; peças muito compridas tinham continuação indicada por uma seta; partes muito semelhantes que continham frente e costas eram um único molde, com apenas algumas linhas diferenciando os dois lados. Além das instruções para desenhar o molde, o periódico também publicava os desenhos de molde final de algumas peças descritas, como é possível ver na Figura 5.

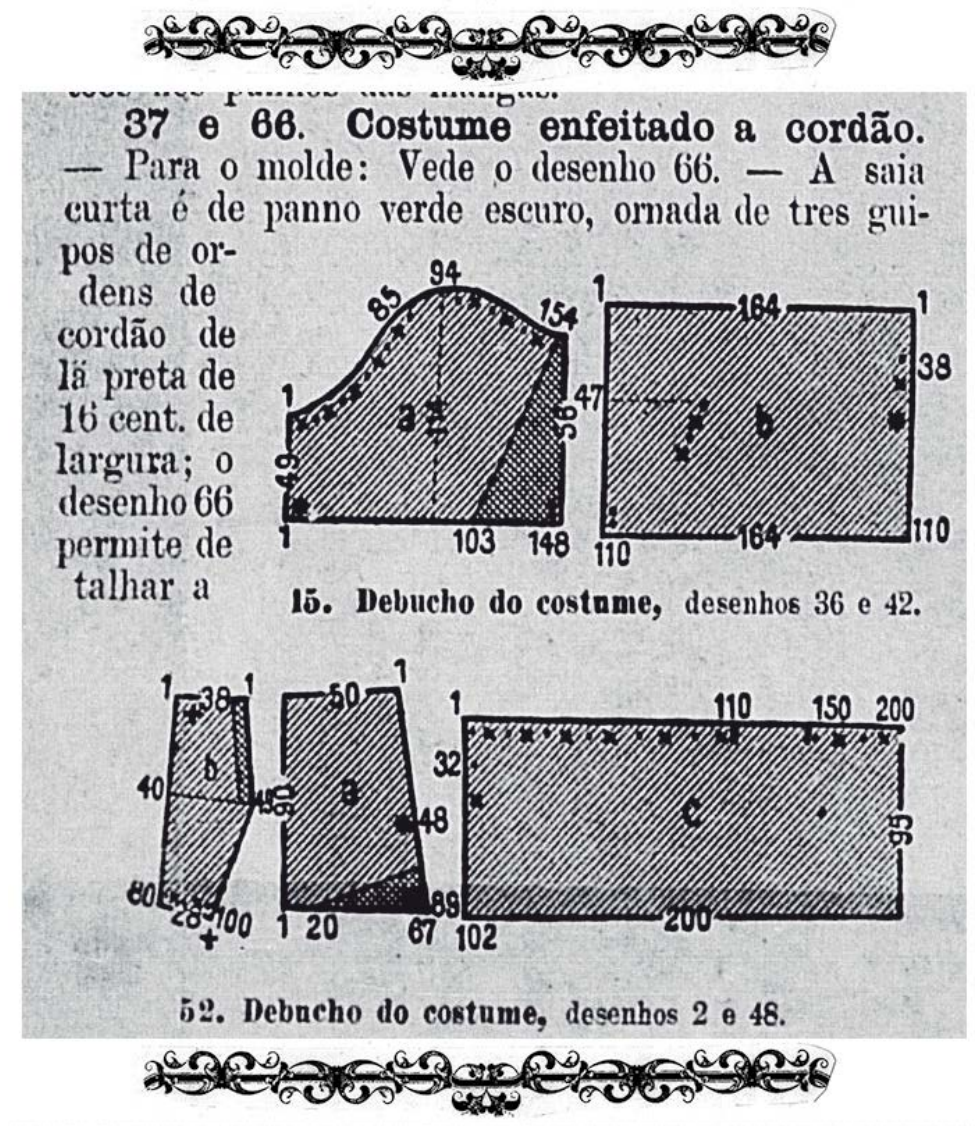

Figura 5 - Exemplo de desenho de molde. A Estação, n. 1, p. 6, p. 16. Fonte: Hemeroteca Digital 
A primeira edição de I899, comparada às outras, traz uma mudança na disposição das páginas. Inicia-se com uma espécie de capa com imagens de quatro senhoras com vestidos elaborados e, então na segunda página, consta a seção Correio da Moda, assinada por Paula Candida, também com algumas mudanças.

As edições anteriores continham poucas figuras relacionadas ao assunto de moda abordado; essa possui figuras que auxiliam o leitor a visualizar os modelos comentados e descritos. Paula Candida comenta vestidos de bailes, chás e em cada figura da página podem-se encontrar elementos mencionados por ela, como as rosetas e tecidos listrados.

O destaque dessa edição são peças que podem ser usadas em passeios em geral, comentando as novidades de estilo do momento. É citada uma saia para teatros e jantares, com recortes e tipos de fechamentos diferentes, chamada Luís XVI, mais apertada "nas cadeiras", mas com tecido suficiente para que a parte de trás fosse mais elaborada. Para combinar com as saias, era indicado um casaco de "guipure", fechado com "bonitas joias familiares" ou "flores de cassa ${ }^{8}$ de seda" (A ESTAÇÃO, n. I, I899, p. 2). Também são comentadas as "tea jackets", casacos especiais para o chá das cinco ("five o'clock", copiando o costume inglês), que, já que se assemelhavam mais a uma blusa que a uma jaqueta, Paula Candida acreditava que iriam substituir as blusas usadas por todas as mulheres.

A segunda edição de I899 informa sobre uma nova moda que surge: casaca à Luís XVI. Descreve-o como um casaquinho guarnecido de peles nas laterais e renda na parte da frente. E não foi apenas essa peça que foi confeccionada com peles. Segundo Paula Candida, as peles estavam em alta entre as parisienses - "Uma outra invenção, bem fantastica” (A ESTAÇÃO, n. 2, I899, p. Io) - usando animais em volta do pescoço como echarpes e até inventando novas maneiras de usá-los que pudessem inovar no visual.

\section{O COMPORTAMENTO INFLUENCIADO PELOS PERIÓDICOS}

Como se lê na primeira página de $O$ Espelho Diamantino, o pioneiro em dedicar-se ao público feminino no Brasil, a moda é considerada um tema essencial - e até mesmo sagrado - para as mulheres. Porém, esse fato não impede que as colunas de moda tenham uma vida curta nas publicações oitocentistas - considerando que conseguem sobreviver no mercado de imprensa. Os periódicos estavam começando a ganhar espaço no Brasil, muitas pessoas se inseriam nesse novo meio de comunicação, mas não conseguiam mantê-lo vivo, saindo - como o próprio O Espelho Diamantino - de circulação em curto período de publicação, ou extinguiam aos poucos a coluna sobre determinados assuntos, nesse caso a moda.

Conforme os anos passavam e as mudanças no vestuário aconteciam mais intensa e rapidamente, os periódicos femininos podiam contar com colunas de moda mais completas e frequentes. Pode-se confirmar esse fato comparando o conteúdo de vestuário nos periódicos da primeira metade com os da segunda metade do século.

8 Tecido fino de algodão ou linho (PUELLES, 20I4). 
A Estação é um exemplo que acompanhou mudanças desde o final da década de I870 e conseguiu sobreviver até o início do século XX.

Dessa maneira, é possível perceber uma relação de influência por parte dos periódicos para que ocorressem mudanças na indumentária: se não houvesse mudanças no vestuário, não haveria conteúdo para a coluna de moda nos periódicos, que, portanto, poderiam perder leitoras.

Quanto ao assunto que mais se repete entre os periódicos analisados, tem-se a diferença climática entre a Europa e a América do Sul, apresentada como um grande empecilho para que as brasileiras acompanhassem a moda europeia. Isso fazia com que a moda no país sempre estivesse atrasada em relação à moda parisiense, como é mencionado já em I827 n'O Espelho Diamantino: todas as peças importadas que chegavam ao Brasil eram o resto da moda francesa. A questão climática é, também, um dos motivos para os periódicos proporem adaptações dos modelos estrangeiros, em relação tanto à modelagem quanto aos materiais. Para Christina - que escrevia para $O$ Jornal das Senhoras - o clima não era tanto um problema, uma vez que não acreditava que as brasileiras tinham capacidade de criar modelos originais, prestigiando o talento dos franceses. Dessa forma, posiciona-se a favor da importação de peças e consequente cópia de modelos, através da disponibilização de moldes.

O Jornal das Senhoras foi o primeiro periódico feminino redigido apenas por mulheres, sendo lançado em I852. O fato de que apenas mulheres contribuíam para esse periódico pode ser considerado uma maneira de criar uma relação mais íntima com as leitoras, seja pelos assuntos tratados, seja pela linguagem de escrita, uma vez que elas conheciam bem o universo feminino, além de ter extrema importância na participação feminina em um mercado de imprensa que por muitos anos, até mesmo depois da extinção desse periódico, foi majoritariamente dirigido por homens.

Como visto durante a pesquisa bibliográfica, antes da década de I850 não existiam ainda, no Brasil, ilustrações de moda nos periódicos. O Jornal das Senhoras foi também um dos pioneiros em disponibilizar ilustrações - também estrangeiras - para suas leitoras. A Estação também merece destaque quanto às ilustrações, uma vez que o periódico foi revolucionário em comentar as ilustrações da edição, assim como em publicar ilustrações não apenas de um figurino em moda, mas de várias peças tanto de vestuário como de acessórios, mobiliário e utensílios para casa, com instruções para confecção, detalhes de materiais e também moldes. Essa publicação foi pioneira nesse século e não é por acaso que teve uma longa vida, avançando até o início do século XX.

\section{CONSIDERAÇõES FINAIS}

\section{Clima como o principal empecilho para a moda}

A diferença climática era um dos principais problemas para as brasileiras do século XIX, que, além de se sentirem sempre atrasadas em relação à moda europeia, tinham ou que usar roupas de inverno no verão tropical ou adaptá-las. O papel dos periódicos como auxílio nessas adaptações é importantíssimo, uma vez que ao disponibilizar informações de materiais e moldes instruíam as leitoras na confecção das peças. 
Atualmente ainda existe uma visão de que a moda chega com atraso no Brasil, mas, por outro lado, o amplo mercado permite que também existam criações nacionais que não dependem totalmente da moda estrangeira.

\section{Os periódicos oitocentistas como fonte de documentação da história da moda}

Pode-se afirmar que os periódicos brasileiros do século XIX são fonte essencial de documentação da história da moda, porém não de uma moda puramente brasileira. Eles registram a evolução da moda francesa, além de confirmar sua expansão global. O vestuário no Brasil oitocentista - como se pode ver pela análise dos periódicos - era totalmente dependente do vestuário europeu, pois ainda não havia criações genuinamente brasileiras.

No entanto, as sugestões de adaptações de modelos - seja quanto aos materiais, seja quanto à modelagem - são uma primeira tentativa de caracterizar o vestuário como brasileiro, criando o início de uma cultura de vestir mais nacional que estrangeira, que ganhará força e espaço no século XX.

\section{Os periódicos como impulso para mudanças na moda}

Os periódicos nesse momento da história brasileira são um impulso inicial para o desenvolvimento de uma imprensa mais acelerada. Mas também são uma pressão para mudanças rápidas na própria moda, a fim de suprir a demanda crescente das leitoras por novidades, criando um mercado tanto de moda como de imprensa. 


\begin{tabular}{|c|c|c|c|}
\hline \multicolumn{4}{|c|}{ PERIÓDICOS FEMININOS BRASILEIROS DO SÉCULO XIX } \\
\hline Periódico & Assunto & Local de publicação & Ano* \\
\hline A Borboleta & $\begin{array}{l}\text { anedotas, literatura, } \\
\text { notícias }\end{array}$ & $\begin{array}{l}\text { Alagoas, Minas } \\
\text { Gerais, Piauí, } \\
\text { Rio de Janeiro, } \\
\text { Sergipe }\end{array}$ & $\begin{array}{l}1844,1857,1859, \\
1860,1876,1888, \\
1891,1892\end{array}$ \\
\hline A Camélia & literatura, notícias, poesia & Rio de Janeiro & 1898 \\
\hline A Chrysalida & $\begin{array}{l}\text { literatura, poesia, } \\
\text { receita,variedades }\end{array}$ & Rio de Janeiro & 1879 \\
\hline A Esmeralda & - & Pernambuco & - \\
\hline A Estação & literatura, moda & Rio de Janeiro & $1879-1904$ \\
\hline A Família & educação, família & $\begin{array}{l}\text { São Paulo, Rio de } \\
\text { Janeiro }\end{array}$ & $1888-1894$ \\
\hline $\begin{array}{l}\text { A Fluminense } \\
\text { Exaltada }\end{array}$ & literatura, notícias & Rio de Janeiro & $1832-1846$ \\
\hline A Grinalda & literatura, recreação & Bahia, Rio de Janeiro & $1861,1869,1870$ \\
\hline A Mai de Família & $\begin{array}{l}\text { bebês, crianças, família, } \\
\text { saúde, vestuário }\end{array}$ & Rio de Janeiro & $1879-1888$ \\
\hline A Mensageira & literatura & São Paulo & 1897,1898 \\
\hline A Mulher & belas-artes, literatura, moda & Nova York & 1881 \\
\hline A Primavera & $\begin{array}{l}\text { arte, indústria, literatura, } \\
\text { teatro }\end{array}$ & Rio de Janeiro & 1861 \\
\hline A Violeta & literatura & São Paulo & 1849 \\
\hline $\begin{array}{l}\text { A Violeta } \\
\text { Fluminense }\end{array}$ & crítica, literatura & Rio de Janeiro & 1857,1858 \\
\hline $\begin{array}{l}\text { Biblioteca das } \\
\text { Senhoras }\end{array}$ & literatura & Rio de Janeiro & 1874 \\
\hline $\begin{array}{l}\text { Correio das Modas, } \\
\text { Jornal Crítico e } \\
\text { Literário }\end{array}$ & $\begin{array}{l}\text { ciência, crítica, literatura, } \\
\text { moda notícias, recreação }\end{array}$ & Rio de Janeiro & $1839-1840$ \\
\hline Echo das Damas & literatura & Rio de Janeiro & $1879,1880,1888$ \\
\hline $\begin{array}{l}\text { Jardim das } \\
\text { Maranhenses }\end{array}$ & $\begin{array}{l}\text { crítica, literatura, moral, } \\
\text { recreação }\end{array}$ & Maranhão & 1861,1862 \\
\hline Jornal das Damas & $\begin{array}{l}\text { charadas, instrução, } \\
\text { recreação, variedades }\end{array}$ & Pernambuco & 1862 \\
\hline $\begin{array}{l}\text { Jornal das } \\
\text { Senhoras }\end{array}$ & $\begin{array}{l}\text { belas artes, crítica, } \\
\text { literatura, moda, teatro }\end{array}$ & Rio de Janeiro & $1852-1855$ \\
\hline $\begin{array}{l}\text { Marmota } \\
\text { Fluminense }\end{array}$ & moda, variedades & Rio de Janeiro & $1854-1858$ \\
\hline $\begin{array}{l}\text { Mentor das } \\
\text { Brasileiras }\end{array}$ & $\begin{array}{l}\text { comportamento, crítica, } \\
\text { educação, história }\end{array}$ & Minas Gerais & 1829-1832 \\
\hline
\end{tabular}




\begin{tabular}{|c|c|c|c|}
\hline $\begin{array}{l}\text { Novo Correio de } \\
\text { Modas }\end{array}$ & $\begin{array}{l}\text { charadas, história, } \\
\text { literatura, moda, novelas, } \\
\text { poesia }\end{array}$ & Rio de Janeiro & $1852-1854$ \\
\hline O Beija-Flor & literatura, notícias, poesia & Alagoas & 1869,1870 \\
\hline O Bello Sexo & literatura, recreação & Pernambuco & 1850,1851 \\
\hline $\begin{array}{l}\text { O Bond: Jornal das } \\
\text { Moças }\end{array}$ & & - & - \\
\hline O Cherubim & $\begin{array}{l}\text { charadas, literatura, moda, } \\
\text { recreação }\end{array}$ & Rio de Janeiro & $1885-1887$ \\
\hline $\begin{array}{l}\text { O Espelho das } \\
\text { Bellas }\end{array}$ & literatura, recreação & Bahia & 1860,1861 \\
\hline $\begin{array}{l}\text { O Espelho das } \\
\text { Brasileiras }\end{array}$ & literatura, notícia & Pernambuco & 1832 \\
\hline $\begin{array}{l}\text { O Espelho } \\
\text { Diamantino }\end{array}$ & $\begin{array}{l}\text { belas artes, literatura, } \\
\text { moda, política, teatro }\end{array}$ & Rio de Janeiro & 1827,1828 \\
\hline $\begin{array}{l}\text { O Espelho } \\
\text { Fluminense }\end{array}$ & $\begin{array}{l}\text { charadas, literatura, moda, } \\
\text { poesia. }\end{array}$ & Rio de Janeiro & 1843 \\
\hline O Leque & literatura, notícia, poesia & Minas Gerais, Sergipe & 1890,1897 \\
\hline O Lírio & notícias, variedades & São Paulo & 1860 \\
\hline O Ramalhete & literatura, variedades & Maranhão & 1863,1864 \\
\hline $\begin{array}{l}\text { O Quinze de } \\
\text { Novembro do Sexo } \\
\text { Feminino }\end{array}$ & $\begin{array}{l}\text { literatura, notícia, } \\
\text { recreação }\end{array}$ & Rio de Janeiro & 1889,1890 \\
\hline O Sexo Feminino & literatura, notícia & Minas Gerais & $\begin{array}{l}1873,1874,1875 \\
1889\end{array}$ \\
\hline Recreio das Moças & $\begin{array}{l}\text { charadas, ciência, } \\
\text { literatura, poesia, } \\
\text { variedades }\end{array}$ & Rio de Janeiro & 1876,1877 \\
\hline $\begin{array}{l}\text { Recreio das } \\
\text { Senhoras }\end{array}$ & $\begin{array}{l}\text { belas artes, instrução, } \\
\text { literatura, moda, poesia, } \\
\text { teatro }\end{array}$ & Bahia & 1861 \\
\hline $\begin{array}{l}\text { Recreio do Bello- } \\
\text { Sexo }\end{array}$ & $\begin{array}{l}\text { belas artes, literatura, } \\
\text { moda, teatro }\end{array}$ & Rio de Janeiro & 1856 \\
\hline Revista das Moças & - & - & - \\
\hline O Álbum Semanal & crítica, literatura, moda & Rio de Janeiro & 1851,1852 \\
\hline
\end{tabular}

Tabela I - Relação dos periódicos femininos brasileiros do século XIX (elaborada pelas autoras).

${ }^{*}$ Refere-se aos anos disponíveis para consulta na Hemeroteca Digital 
BEATRIZ ALBAREZ DE ASSUNÇÃO é mestranda em Têxtil e Moda na Escola de Artes, Ciências e Humanidades da Universidade de São Paulo (EACH/ USP).

E-mail: beatriz.assuncao@usp.br

ISABEL CRISTINA ITALIANO é livre-docente de graduação e pós-graduação em Têxtil e Moda da EACH/USP. Desenvolve suas pesquisas na área de alfaiataria e modelagem de trajes históricos, têxteis tecnológicos e computadores vestíveis.

E-mail: isabel.italiano@usp.br

\section{REFERÊNCIAS}

A ESTAÇÃO: jornal illustrado para a familia. Rio de Janeiro: Livraria e Typografia Lombaerts \& Comp., I879-I899. Disponível em: <bndigital.bn.br/hemeroteca-digital〉. Acesso em: I3 mar. 2015.

BOUCHER, F. História do vestuário no Ocidente. São Paulo: Cosac Naify, 2010.

BRAGA, J.; PRADO, L. A. História da moda no Brasil: das influências às autorreferências. 2. ed. São Paulo: Disal, $20 I I$.

BUITONI, D. Imprensa feminina. São Paulo: Ática, I986.

CHATAIGNIER, G. História da moda no Brasil. I. ed. São Paulo: Estação das Letras e Cores, 2010.

COSTA, C. A revista no Brasil do século XIX. São Paulo: Alameda, 2012.

HEMEROTECA Digital. Acervo de periódicos da Fundação Biblioteca Nacional. Disponível em: <bndigital. bn.br/hemeroteca-digital>. Acesso em: 27 ago. 2018.

LAVER, J. A roupa e a moda: uma história concisa. São Paulo: Companhia das Letras, I989.

LIPOVETSKY, G. O império do efêmero: a moda e seu destino nas sociedades modernas. São Paulo: Companhia das Letras, 2009.

O ESPELHO Diamantino: periodico de politica, litteratura, bellas artes, theatro e modas. Rio de Janeiro: Imperial Typographia de P. Plancher-Seignot, I827. Disponível em: <bndigital.bn.br/hemerotecadigital>. Acesso em: 27 mar. 2015.

O JORNAL das Senhoras: modas, litteratura, bellas-artes, theatros e critica. Rio de Janeiro: Typographia Parisiense, I852-I855. Disponível em: <bndigital.bn.br/hemeroteca-digital 〉. Acesso em: 28 mar. 2015. PUELLES, A. A. L. O vestuário e seus acessórios em São Paulo em meados do século XIX: uma construção do vocabulário para compreender a indumentária. Dissertação (Mestrado em Museologia). Programa de Pós-Graduação Interunidades em Museologia, Universidade de São Paulo. São Paulo, 20I4. SOUZA, G. M. O espírito das roupas: a moda no século dezenove. São Paulo: Companhia das Letras, I987. 